Revista Aspas

ppgac - USP

Desenhos de Pesquisa

\title{
RASTROS METODOLÓGICOS PARA POÉTICAS HÍBRIDAS: DA CRÍTICA GENÉTICA, ENTRE PROVOCAÇÕES (AUTO)ETNOGRÁFICAS, À CARTOGRAFIA
}

\author{
METHODOLOGICAL TRACES FOR HYBRID POETICS: \\ FROM GENETIC CRITICISM, AMONG (AUTO)ETHNOGRAPHIC \\ PROVOCATIONS, TO CARTOGRAPHY \\ PISTAS METODOLÓGICAS PARA POÉTICAS HÍBRIDAS: \\ DE LA CRÍTICA GENÉTICA, ENTRE PROVOCACIONES \\ (AUTO)ETNOGRÁFICA, A LA CARTOGRAFÍA
}

\section{Vinícius Lírio}

Vinícius Lírio

Doutor em Artes Cênicas (2014) pelo Programa de Pós-Graduação em Artes Cênicas (PPGAC) da Universidade Federal da Bahia (UFBA). Mestre em Artes Cênicas (2011) e graduado em Licenciatura em Teatro (2005) pela UFBA. Atualmente, é professor adjunto da Universidade Federal de Minas Gerais (UFMG), atuando nos cursos de Licenciatura em Teatro, Pedagogia e no Mestrado Profissional Educação e Docência (Promestre). Encenador e ator. 


\section{Resumo}

Este estudo apresenta uma rede de rastros das abordagens metodológicas utilizadas pelo autor em suas pesquisas de mestrado e doutorado e na sua atual investigação. Estas têm em comum o fato de partirem de processos criativos no teatro contemporâneo. Articulamse, aqui, princípios da Crítica Genética, das abordagens etnográfica e autoetnográfica e do método cartográfico. A partir da sistematização dessa trama, busca-se compartilhar possíveis caminhos, seus rastros e as articulações destes na atual pesquisa do autor, no sentido de mapear poéticas híbridas.

Palavras-chave: Autoetnografia, Etnografia, Método cartográfico, Pesquisa em artes cênicas.

\section{Abstract}

This study presents a network of traces of the methodological approaches used by the author in his master's and doctoral researches and his current investigation. These have in common the fact of starting from creative processes in contemporary theater. Principles of Genetic Criticism, ethnographic and autoethnographic approaches and the cartographic method are articulated herein. From the systematization of this web, one seeks to share possible paths, their traces and articulations thereof in the author's current research, in which he uses them to map hybrid poetics.

Keywords: Autoethnography, Ethnography, Cartographic method, Research in performing arts.

\section{Resumen}

Este estudio presenta pistas de los enfoques metodológicos utilizados por el autor en sus investigaciones de maestría, de doctorado y en su actual investigación. Lo que tienen en común es el hecho de partir de procesos creativos en el teatro contemporáneo. Para ello, se articulan los principios de la crítica genética, de los enfoques etnográficos y autoetnográficos y del método cartográfico. Desde la sistematización de esta trama, se busca compartir posibles caminos, sus pistas y las articulaciones de éstos en la actual investigación del autor para mapear poéticas híbridas.

Palabras clave: Autoetnografia, Etnografía, Método cartográfico, Investigación en Artes Escénicas. 
Desde que iniciei minha trajetória no teatro, em 2000, deparei com a pesquisa como meio e princípio para imergir naquele emaranhado de vetores que compunha essa expressão artística e sua constituição enquanto campo do conhecimento. Quando mergulhei nesse campo, não sabia por onde começar, como sistematizar os estudos e articular uma pesquisa que envolvesse essas dimensões. Tais inquietações me acompanham desde então, pois entendi que elas, entre tantas outras, atravessam minhas práticas com a pesquisa no campo das artes cênicas, sejam elas artísticas, acadêmicas ou artístico-acadêmicas.

Logo, essa provocação inicial foi determinante na minha trajetória como artista-pesquisador-professor no campo das artes cênicas. De lá para cá passei a transitar por esses lugares, ora de forma mais orientada, com alguma indicação de professores, ora de forma mais intuitiva. Nesse passo, cheguei ao Programa de Pós-Graduação em Artes Cênicas da Universidade Federal da Bahia (UFBA), onde desenvolvi minhas pesquisas de mestrado e doutorado.

Minha primeira pesquisa partia do acompanhamento do processo criativo do espetáculo Bença, do Bando de Teatro Olodum ${ }^{1}$, durante o ano de 2010. Já naquele início de percurso, a primeira problemática que surgiu diante das demandas da investigação foi: como sistematizar um estudo considerando as especificidades de uma poética, sem subvertê-la a teorias já fundadas? Como estabelecer a relação entre teorias do teatro, a prática teatral em si e a visão que se lança sobre essa prática a partir de conjecturas teórico-epistemológicas?

Questões voltadas para abordagens metodológicas como essas deram origem ao primeiro texto acadêmico fruto daquela pesquisa, intitulado "Da névoa ao límpido: pistas sobre o processo de pesquisa em Artes Cênicas" (LÍRIO, 2010). Esse texto traz reflexões embrionárias e é marcado muito mais por provocações - a mim e aos meus pares pesquisadores - que por respostas, as quais seriam impossíveis naquele momento.

O que esse primeiro esforço de teorização já me sinalizava é que, diante de poéticas específicas - que têm constituído o universo das minhas

1. O Bando de Teatro Olodum surgiu no início dos anos 1990, em Salvador (BA), com o objetivo de produzir um teatro fincado nas raízes da cultura baiana, relacionando-a à contemporaneidade. 
pesquisas - há demanda de considerar os seus traços, as vozes que as atravessam, seus sujeitos, seus procedimentos, suas articulações e seus desdobramentos estéticos.

Para tanto, nesse caminho como pesquisador, venho articulando redes por meio de princípios da Crítica Genética (SALLES, 2008, 2009), das abordagens metodológicas etnográfica e autoetnográfica (ANDRÉ, 2005; FORTIN, 2009; REED-DANAHAY, 1997; VERSIANI, 2005) e do método cartográfico (DELEUZE; GUATTARI, 2000; MACHADO, 2016; PASSOS; BARROS, 2015). Mapeemos alguns vetores dessas propostas a partir das investigações com processos criativos, que venho desenvolvendo nos últimos sete anos.

\section{Rastros de caminhos percorridos: da Crítica Genética a etnografias de poéticas}

Em comemoração aos vinte anos de existência do Bando de Teatro Olodum foi criado Bença, um "espetáculo instalação", fruto do processo de criação sobre o qual lancei meus olhares no decorrer do ano de 2010, como parte de minha pesquisa de mestrado em artes cênicas.

Para tratar dessa poética, das referências culturais e dos procedimentos entrecruzados no teatro feito pelo Bando, naquela oportunidade, investi numa articulação entre: os rastros (memórias e registros de situações no processo de criação e na encenação em si), os fenômenos da cena (reflexões acerca do conjunto de rastros suscitados a partir de práticas e estudos no campo das artes cênicas, especialmente o teatro, buscando um trânsito fluido e recíproco entre as situações e seus sujeitos e a minha percepção enquanto pesquisador) e os aportes teórico-epistemológicos (teorias do teatro, das ciências humanas - sociologia e antropologia, em especial - e da filosofia, às quais tive acesso no contexto da pesquisa, e constatações oriundas das formulações dos sujeitos agentes acerca da sua prática).

É importante ressaltar que esses rastros foram recuperados por meio de diversos documentos de processo, pelas vozes dos sujeitos deste, pelos meus registros em diários de bordo, ao longo do ano de observação direta do movimento criativo e, ainda, a partir das minhas percepções acerca de situações referenciadas nesse processo criativo e na encenação em si, bem 
como nas epistemologias oriundas da compreensão dos sujeitos acerca de sua poética, à luz do meu olhar e, portanto, já filtradas por ele.

Da trama reflexiva desdobrada desses rastros, depois de análise das descrições minuciosas dos registros feitos por mim em diários, a partir das situações do processo, foram sinalizados o que chamei de fenômenos da cena, para somente então implementar um esforço de teorização e sistematização dos estudos num diálogo com teorias e reflexões externas àquela poética.

Percebi, no exercício de elaboração desse instrumento/procedimento que constitui o diário de bordo, a sua relevância e contribuição metodológica, especialmente quando lidamos com um trabalho em processo. Nesse sentido, concordo com Machado (2002, p. 262) quando ela propõe que "um diário de bordo bem realizado é, portanto, algo que documenta processos de criação, e que acaba por ganhar, como texto, 'vida própria', funcionando como ferramenta de concomitantes aproximação e distanciamento do trabalho processual".

Tendo caráter de intimidade, esse recurso de registro, segundo Versiani (2005, p. 69), configura ainda meios de autoconstrução de subjetividades, podendo, deste modo, "ser lidos como textos com valor de etnografia e vice-versa, havendo entre as duas formas de escrita (auto e etno - grafias) aspectos intercambiáveis". Daí o seu caráter tão presente nas pesquisas com as poéticas híbridas com as quais venho lidando.

Investi num percurso tateante, tanto por seu caráter indefinido como pelo fato de se configurar, gradualmente, a partir das condições potenciais do próprio pensamento. Isso já me colocava em contato com um dos princípios do método cartográfico, ainda que, naquele momento, suas diretrizes não aparecessem de forma sistemática na pesquisa.

Nesse passo, fiz-me valer, no percurso daquela sistematização acadêmica, da visão trazida por Ângela Materno (2003) quanto ao que a teoria traz para todas as pesquisas: ela lança, sobre um determinado objeto, visões de mundo e formas de conhecimento específicas que, tensionadas, dão forma ao que ela chama de teorização.

Segundo essa proposta, teorizar implicaria uma dialogia reflexiva a fim de articular a formação de conceitos e perspectivas de abordagens com as posturas críticas a partir do espaço-tempo onde a problematização emerge. Naquele caso, seria a sala de ensaios João Augusto, no Teatro Vila Velha, 
em Salvador - Bahia, onde foram esboçadas as situações cênicas de Bença: campo de atualização da teatralidade do Bando de Teatro Olodum.

Em 2012, dois universos atravessados por matizes culturais vários, por multiplicidades e identificações continuamente criadas e recriadas, hibridizaram-se no teatro. Esse movimento ocorreu no processo de criação do espetáculo $D O ̂$, também do Bando de Teatro Olodum, com direção do mestre de butô, Tadashi Endo.

A abordagem desse processo criativo, no meu percurso de doutoramento, embora partisse de princípios similares aos da pesquisa do mestrado, verticalizava algumas diretrizes metodológicas de modo mais amadurecido e sistematizado que na pesquisa anterior.

Estava em um estudo avançado a partir de outros processos criativos, mas resolvi recomeçar. Não por achar que este ou aqueles tinham algo de menos ou a mais para oferecer. Mas por responder a um desejo que me mobilizou enquanto pesquisador e homem de teatro. Acho que a pesquisa é feita também por essas vias dos afetos e das identificações.

Diante disso, fui procurar o Bando para pensar meios de acessar o processo, que já havia começado e estreado, ainda que somente pelo seu discurso. Eles tinham vasto material audiovisual de registro das visitas de Tadashi e dos trabalhos realizados com ele. Minhas reflexões foram desenvolvidas a partir da apreciação dessas imagens. Agregados a isso, em muitos vídeos e textos publicados (inclusive no programa do espetáculo) havia depoimentos e reflexões dos sujeitos agentes de $D O ̂$ sobre esse processo, aos quais assisti diversas vezes.

Por fim, para manter diálogo mais direto, entrevistei dois dos atuantes de DÔ, Leno Sacramento e Valdinéia Soriano, e o próprio Tadashi Endo. Além disso, mantive conversas informais com os demais atuantes e diretores do Bando a fim de entender por meio de suas vozes como se deu o processo. Em maio de 2013, tive a única oportunidade presencial de apreciar um ensaio de DÔ.

Concentrei-me no fenômeno: em seus processos e procedimentos, no seu espaço-tempo e em seus sujeitos agentes. De que forma aquele projeto cênico foi criado? De que maneira se deram as conexões, os agenciamentos e as articulações entre os desejos dos criadores envolvidos? As respostas estavam no ato criador. Sendo este inacabado, esse estudo - assim como o 
que desenvolvo aqui - foi também construído em movimento e mantém caráter provisório. Como uma imagem em metamorfose, que ganhou seus traços móveis a partir de um olhar e de múltiplas vozes. Investi na compreensão da tessitura que atravessou essa obra e o seu devir criativo.

A abordagem dessa poética se deu através do conjunto de ações citado há pouco e foi o que me permitiu, com a apreciação do espetáculo, vislumbrar os rastros dessa criação, identificar o que chamo de "fenômenos da cena" e, só então, investir numa sistematização de pensamentos e articulações de vozes no escopo de um estudo, conforme já sinalizei aqui.

A utilização do termo "rastro" advém do sentido levantado por Salles (2009, p. 23-24), segundo o qual toda obra de arte é reintegrada continuamente na cadeia ininterrupta do percurso criador. Segundo essa estudiosa, criadora do Centro de Estudos de Crítica Genética, por a obra estar em mudança permanente, restam os seus índices. Então o estudo da dinâmica desses índices de uma "história" e do sentido da mudança, para compreender o todo, seriam como um "manuseio de rastros", tal qual o fazem arqueólogos, geólogos e historiadores.

Nesse ponto, torna-se importante recuperar alguns princípios da Crítica Genética. Essa abordagem dos processos de criação no campo das artes seria desenvolvida por uma espécie de mergulho nos "esboços" - a gênese do ato criativo - para conhecer o nascimento, os movimentos e as relações que a obra viria a estabelecer.

À luz de entendimentos dessa ordem é que se pode afirmar que "a Crítica Genética surgiu com o desejo de melhor compreender o processo de criação artística, a partir dos registros desse seu percurso deixados pelo artista" (SALLES, 2008, p. 20-21).

Alguns dos princípios presentes nessa abordagem me colocam diante de registros do processo criador de diversas naturezas. Para Salles (2009), tais elementos do processo configuram "retratos" de uma gênese que, dentre os vetores metodológicos sugeridos aqui, servem como índices de um percurso criativo.

Olhando especificamente para os processos no campo do teatro e das poéticas, as definições sobre o que seriam esses registros, tal como é a cena, configuram algo móvel e efêmero. Na sistematização da minha tese de 
doutoramento, estabeleci um esforço dialógico entre o que foi registrado pelos sujeitos do processo de criação de $D O \hat{O}$ (vídeos, relatos, fotografias), o que aconteceu (os rastros do ato criativo em si, aos quais tive acesso por meio de vídeos feitos durante o processo) e, ainda, as memórias compartilhadas por eles acerca de sua criação.

A dinâmica de articulações no escopo desse trabalho não encerra o que foi a poética. Por isso, insisto em me colocar - aqui e em outras teorizações, como as que venho citando - em primeira pessoa: para reforçar que esta é apenas uma teia de reflexões, um olhar que foi sendo elaborado no que também entendo como um processo criativo. Assim também compreende Salles (2009, p. 26), ao afirmar que "cada processo é singular na medida em que as combinações dos aspectos que serão aqui discutidos, são absolutamente únicas."

\section{(Auto)etnografias e cartografias: dos percursos tateantes das poéticas}

Na minha atual pesquisa, intitulada "Cartografia de poéticas híbridas", bem como na investigação que tem atravessado meu projeto de ensino com alunos da Licenciatura em Teatro, da Universidade Federal de Minas Gerais (UFMG), tenho investido no que chamo de "provocações (auto)etnográficas" para construção de mapas de poéticas: na pesquisa, daquelas marcadas por hibridismos entre expressões artísticas (teatro, dança, performance e intervenção urbana) e manifestações culturais espetaculares; no ensino, voltando-se para a formação de professores de teatro, no sentido de criar memória, registro, sistematização e acompanhamento de suas poéticas da sala de aula.

Para tanto, esses investimentos envolvem dimensões e abordagens que, em rede, configuram uma dinâmica transversal, instável, flexível, porosa e em movimento, articulando etnografia, autoetnografia e a construção de cartografias.

O uso dessas abordagens surge de uma primeira provocação: como animar, nesses contextos de pesquisa, um movimento criativo das vozes dos sujeitos que a integram e a desenvolvem, e, ao mesmo tempo, já apresentasse uma possível perspectiva e justificativa conceitual, metodológica e pedagógica para suas imersões, intervenções e sistematizações de processos? 
Lançada essa fagulha provocadora, retornei ao problema de encontrar uma forma de registro dinâmica e que pudesse abrigar tempos, espaços, interações, teorias, vozes e transformações. Nesse cenário surgiu a cartografia. Após já ter investigado e experimentado a construção de relatórios, ensaios acadêmicos, "nuvens pictóricas", "nuvens de palavras-chaves" e "mapas conceituais", resolvi buscar algo que unisse tudo isso e que pudesse ser construído enquanto os fenômenos estavam acontecendo naquelas poéticas, e que eles mesmos gerassem o universo de análises e interpretações: cartografias de poéticas.

Nesse passo, encontramos o que Machado (2016, p. 14) entende como "desenho-em-palavras", um instrumento capaz de articular descrições, temas e interpretações criativas de processos experienciados: os mapas. Segundo a autora, esses instrumentos cartográficos têm o potencial de revelar as "poéticas próprias" - universo que envolveria dados biográficos, artísticos e intelectuais de cada sujeito - e, a partir disso, construiria discursos como parte de uma metodologia etnográfica. O mapa configuraria, no nosso caso, uma rede imagética norteadora para análise das práticas desenvolvidas e registradas, sejam de poéticas de outros sujeitos ou próprias, como aquelas dos alunos da licenciatura em seus processos de estágio docente.

Com essa compreensão, os mapeamentos de poéticas - cujas construções venho estimulando - são estruturados e desdobrados considerando princípios do método cartográfico, como proposto por Deleuze e Guatarri (2000), na medida em que se reconhece sua força performática, sendo aberto à incorporação dos saberes e fazeres, dos afetos e atravessamentos dos processos deflagradores dessa investigação e de seus sujeitos.

Nesse sentido retomo, nesses lugares, o acesso a diários de bordo e a criação de novos destes, bem como outros tipos de registros possíveis (audiovisual, rascunhos, desenhos, esquemas, relatos etc.), que seriam recursos para o desenvolvimento de nossas (auto)etnografias. Nesse sentido, compartilho do pensamento de Macedo de Sá (2012, p. 75), que compreende que a etnografia é uma "prática descritiva cultural, sensível e aprendente", numa postura descritiva do pesquisador, tanto no que concerne à dimensão teórico-metodológica quanto à ética e à política, a fim de compreender os sentidos e significados das ações dos sujeitos e de suas atividades culturais. 
Ainda nesse percurso, recorro à autoetnografia. Considerada parte da metodologia etnográfica, sua abordagem, desde o princípio, fez-se oportuna pela "zona de fronteira" (REED-DANAHAY, 1997), na qual se localizam os sujeitos dos processos abordados nesse texto, isto é, entre o contexto deflagrador desse estudo (as disciplinas mediadas pelo autor), o universo sociocultural estudado e, ainda, os processos criativos implicados em ambos os casos. Esse lugar fronteiriço surge no próprio ato investigativo e à medida que o pesquisador, ao investir no registro e na sistematização, realiza suas autonarrativas, analisa e interpreta os fenômenos reconhecidos no universo em estudo.

As informações obtidas nessas experiências investigativas, pedagógicas e criativas, seguidas daquelas oriundas da sua análise e interpretação, foram articuladas em uma rede de dados que envolve afetos, experiências, vozes, teorias, procedimentos, entre outros elementos das poéticas. Essa trama foi deflagradora das cartografias que vêm sendo construídas.

Até este momento, é essa perspectiva que tem atravessado meus processos de pesquisa atual. Esses registros múltiplos atravessam e constituem-se enquanto vetores integrantes e integrados das cartografias aqui propostas como possibilidade metodológica.

\section{Campo de considerações em poética}

Gosto de começar - ou seria encerrar?! - essa parte da escrita com uma frase com a qual inicio a conclusão da minha tese de doutorado: "não há resultado final" (LíRIO, 2014, p. 196).

O modo de articulação no qual investi - e é o que me leva a considerações de natureza provisórias, em poética - toma os elementos implicados nessa abordagem metodológica num enfoque dinâmico ou, como sugere Salles (2009, p. 24, grifo meu), "sob o prisma do movimento". Assim esse estudo e aqueles que o geraram se colocam: como uma "obra do tempo", uma rede de reflexões minhas, em/de determinada conjuntura, sobre abordagens, processos e fenômenos específicos - aqueles das poéticas implicadas nas pesquisas trazidas - que atravessam o espaço-tempo contínuo e não linear de uma criação, tal como se constitui este mapeamento. 
Lidar com essa continuidade, desse tempo que é também multilinear e que não se fecha, me dá a liberdade para permanecer no que Salles (2009) chama de "estética do inacabamento". Eis o que justifica, aqui, a construção de reflexões e considerações apenas provisórias, isto é, em poética. Para isso recorri a elementos que "permitem a ativação da complexidade do processo. Não guardam verdades absolutas, pretendem, porém, ampliar possibilidades de discussão sobre o processo criativo" (Ibid., p. 25).

É assim que as abordagens metodológicas que utilizei e os espaços que tenho criado, nas sistematizações dos estudos, têm me possibilitado dialogar e refletir com os fenômenos, as percepções, as teorias e as práticas emergidas dos projeto poéticos. Transito nesses lugares levantando discussões que surgem dos vetores de cada um desses processos e que têm contribuído, no caso das minhas pesquisas, para pensar poéticas híbridas.

Assim, o movimento ao qual venho me lançando nos últimos anos surge como um corpo construído para explorar as potencialidades de campos intersticiais, intervalares, transitórios. E, dessa forma, cada estudo deflagrado e deles desdobrado constitui-se apenas enquanto um na multiplicidade de outros tantos possíveis. Um corpo em fluxo, em atualização a cada linha e que se mantém em abertura. Campo de reflexões em poética.

\section{Referências bibliográficas}

ANDRÉ, M. E. D. A. Etnografia da prática escolar. 12. ed. Campinas: Papirus, 2005.

CANDEIAS, M. L. A cartografia como possibilidade para uma aproximação entre produção artística, crítica e academia. Revista Moringa, João Pessoa, v. 7, n. 1, p. 65-79, 2016.

DELEUZE, G.; GUATTARI, F. Mil platôs: Capitalismo e esquizofrenia. São Paulo: Editora 34, 2000.

FORTIN, S. Contribuições da etnografia e auto-etnografia para a pesquisa na prática artística. Tradução Helena Mello. Cena, Porto Alegre, n. 7, p. 77-88, 2009.

LíRIO, V. S. Da névoa ao límpido: pistas sobre o processo de pesquisa em Artes Cênicas. In: CONGRESSO DA ABRACE, 6., 2010, São Paulo. Anais... São Paulo: Abrace, 2010. Disponível em: <https://goo.gl/QAVokd>. Acesso em: 5 set. 2017.

Poéticas Híbridas: Bando de Teatro Olodum + Butô de Tadashi Endo nos

entre-lugares da criação cênica. 2014. 270 f. Tese (Doutorado) - Programa de Pós-graduação em Artes Cênicas, Universidade Federal da Bahia, Salvador, 2014. 
MACEDO DE SÁ, S. M. Povos indígenas em afirmação, caminhos etnográficos aprendentes e a compreensão cultural de fenômeno aprender. In.: MACEDO, R. S. A etnopesquisa implicada: pertencimento, criação de saberes e afirmação. Brasília, DF: Liber Livro, 2012. p. 75-86.

MACHADO, M. M. O "Diário de Bordo" como ferramenta fenomenológica para o pesquisador em Artes Cênicas. Sala Preta, São Paulo, v. 2, p. 260-263, 2002.

Mapeie-se! E busque de modos criativos de ser e estar no mundo para relacionar-se com a artisticidade das crianças. Teatro: Criação e Construção de Conhecimento, [S.I.], v. 4, n. 5, p. 14-22, 2016. Disponível em: <https://goo.gl/ Q81LdS>. Acesso em: 6 fev. 2017.

MATERNO, A. O olho e a névoa: considerações sobre a teoria do teatro. Sala Preta, São Paulo, n. 3, p. 31-41, 2003.

PASSOS, E.; BARROS, R. B. Pista 1: A Cartografia como método de pesquisa-intervenção. In: PASSOS, E.; KASTRUP, V.; ESCÓSSIA, L. (orgs.). Pistas do método da cartografia: pesquisa-investigação e produção de subjetividade. Porto Alegre: Sulina, 2015. p. 17-31.

REED-DANAHAY, D. Auto/ethnography: rewriting the self and the social. Oxford: Berg, 1997.

SALLES, C. A. Crítica genética: fundamentos dos estudos genéticos sobre o processo de criação artística. 3. ed. rev. São Paulo: Educ, 2008.

Gesto inacabado: processo de criação artística. 4. ed. São Paulo: Annablume, 2009.

VERSIANI, D. B. Autoetnografias: conceitos alternativos em construção. Rio de Janeiro: 7letras, 2005.

Recebido em 15/09/2017

Aprovado em 24/11/2017

Publicado em 03/05/2018 